University of Wollongong

Research Online

Faculty of Social Sciences - Papers (Archive) Faculty of Arts, Social Sciences \& Humanities

2016

\title{
All care, but whose responsibility? Community juries reason about expert and patient responsibilities in prostate-specific antigen screening for prostate cancer
}

Chris Degeling

University of Sydney

Stacy M. Carter

University of Wollongong, stacyc@uow.edu.au

Lucie Rychetnik

University of Notre Dame, lucie.rychetnik@saxinstitute.org.au

Follow this and additional works at: https://ro.uow.edu.au/sspapers

Part of the Education Commons, and the Social and Behavioral Sciences Commons

Research Online is the open access institutional repository for the University of Wollongong. For further information contact the UOW Library: research-pubs@uow.edu.au 


\title{
All care, but whose responsibility? Community juries reason about expert and patient responsibilities in prostate-specific antigen screening for prostate cancer
}

\begin{abstract}
General practitioners have implicitly been given responsibility for guiding men's decisions about prostatespecific antigen-based screening for prostate cancer, but patients' expectations of the bounds of this responsibility remain unclear. We sought to explore how well-informed members of the public allocate responsibilities in prostate-specific antigen screening decision-making. In 2014, we convened two Community juries in Sydney, Australia, to address questions related to the content and timing of information provision and respective roles of patients and general practitioners in screening decisions. Participants in the first jury were of mixed gender and of all ages $(n=15)$; the participants in the second jury were all male and of screening age $(n=12)$. Both juries were presented with balanced factual evidence on the harms and benefits of prostate-specific antigen screening and expert perspectives on ethico-legal aspects of consent in medical practice. In their deliberations, jurors agreed that general practitioners should take responsibility for informing men of the options, risks and benefits of prostatespecific antigen testing, but arrived at different positions on whether or not general practitioners should also guide screening decisions. Jurors also disagreed on how much and when general practitioners should provide detailed information about biopsies and treatments. These responses suggest that for prostate-specific antigen testing, there is a public expectation that both the allocation of responsibility between general practitioners and their male patients, and the level of information provided will be tailored to individual men. In the presence of expert uncertainty, a well-informed public may have reason to embrace or resist shared decision-making processes.
\end{abstract}

\section{Keywords}

expert, about, reason, cancer, juries, prostate, community, responsibility?, whose, but, care, all, screening, antigen, prostate-specific, responsibilities, patient

\section{Disciplines}

Education | Social and Behavioral Sciences

\section{Publication Details}

Degeling, C., Carter, S. M. \& Rychetnik, L. (2016). All care, but whose responsibility? Community juries reason about expert and patient responsibilities in prostate-specific antigen screening for prostate cancer. Health, 20 (5), 465-484. 


\section{All care, but whose responsibility? Community juries reason about expert and patient responsibilities in prostate-specific antigen screening for prostate cancer}

Health

2016, Vol. 20(5) 465-484

(C) The Author(s) 2016

Reprints and permissions: sagepub.co.uk/journalsPermissions.nav DOI: 10.1 I77/I3634593 I6660862 hea.sagepub.com

@SAGE

\title{
Chris Degeling and Stacy M Carter \\ The University of Sydney, Australia
}

\section{Lucie Rychetnik}

The University of Notre Dame Australia, Australia

\begin{abstract}
General practitioners have implicitly been given responsibility for guiding men's decisions about prostate-specific antigen-based screening for prostate cancer, but patients' expectations of the bounds of this responsibility remain unclear. We sought to explore how well-informed members of the public allocate responsibilities in prostate-specific antigen screening decision-making. In 2014, we convened two Community juries in Sydney, Australia, to address questions related to the content and timing of information provision and respective roles of patients and general practitioners in screening decisions. Participants in the first jury were of mixed gender and of all ages $(n=15)$; the participants in the second jury were all male and of screening age $(n=12)$. Both juries were presented with balanced factual evidence on the harms and benefits of prostatespecific antigen screening and expert perspectives on ethico-legal aspects of consent in medical practice. In their deliberations, jurors agreed that general practitioners should take responsibility for informing men of the options, risks and benefits of prostatespecific antigen testing, but arrived at different positions on whether or not general practitioners should also guide screening decisions. Jurors also disagreed on how much and when general practitioners should provide detailed information about biopsies and treatments. These responses suggest that for prostate-specific antigen testing,
\end{abstract}

\section{Corresponding author:}

Chris Degeling, The Centre for Values, Ethics and the Law in Medicine (VELiM), The University of Sydney,

Level I, Medical Foundation Building (K25), Sydney, NSW 2006, Australia.

Email: chris.degeling@sydney.edu.au 
there is a public expectation that both the allocation of responsibility between general practitioners and their male patients, and the level of information provided will be tailored to individual men. In the presence of expert uncertainty, a well-informed public may have reason to embrace or resist shared decision-making processes.

\section{Keywords}

bioethics, cancer and palliative care, organisation of health services, patient-physician relationship, risk and health

\section{Introduction}

The goal of using the prostate-specific antigen (PSA) test as a screening tool is to detect individuals with early-stage cancer so as to offer early and more effective treatment and thus reduce the suffering and death caused by this disease (Moyer, 2012). Yet, the potential for PSA testing in asymptomatic men to promote over-diagnosis and over-treatment causes concern among experts and ongoing controversy. The vast majority of prostate cancers detected through screening are indolent and never cause harm - only a small percentage eventually cause symptoms or death (Chou et al., 2011; Ilic et al., 2011). The PSA test is not highly specific (it will often produce a high reading in the absence of cancer), and current diagnostic procedures have limited capacity to distinguish lifethreatening prostate cancers from the indolent ones. Because of this, there are strongly opposing views about the value of the PSA test for screening asymptomatic men (Wilt et al., 2014).

Professional bodies in the United States, United Kingdom and Australia vary in their recommendations for PSA testing of asymptomatic men for prostate cancer (Pickles et al., 2015). Most clinical guidelines seek to address the uncertainty about the value of PSA testing by recommending that men are fully informed of the potential advantages and disadvantages of PSA screening prior to testing. The US Preventive Services Task Force (USPSTF) and the Royal Australian College of General Practitioners (RACGP) recommendations focus on providing information only to men who initiate the conversation about screening (Knight, 2014). The rationale for advising clinicians to not raise the issue themselves if men haven't asked about the PSA test are uncertainty about the benefits of PSA screening and concerns that men may interpret GPs raising the topic as a recommendation or endorsement. Yet while many experts have deep reservations about PSA screening, research consistently shows that many men do want to be screened or are encouraged to do so by their families (Howard et al., 2013; Squiers et al., 2013). A lot of older men are anxious about the risks of prostate cancer, and many believe it is irresponsible not to be screened (Schwartz et al., 2004).

General practitioners (GPs) are increasingly expected to share decision-making about PSA testing with asymptomatic men. Empirical studies indicate, however, that in practice sharing decisions can be difficult (Mendick et al., 2010; Sinding et al., 2010). Expert assumptions about patients' roles and responsibilities often fail to meet patient's expectations or reflect their experiences (Robertson et al., 2011; Saba et al., 2006). In 2014, we conducted two community juries to explore what different groups of well-informed 
members of the public thought should happen before men decided whether or not to have a PSA test to screen for prostate cancer. We sought information on public expectations of patient and clinician roles and responsibilities, and the moral obligations of GPs, with respect to PSA testing (Degeling et al., 2015b). In this article, we provide a normatively informed qualitative analysis of the jurors' deliberations and outline why attributing responsibility in PSA screening decisions remains a contentious issue.

\section{Background}

Cancer is an emotionally charged issue. Decisions about whether or not to take part in PSA screening for prostate cancer are difficult because of the risks of negative consequences from both testing and non-testing. Because PSA testing almost always takes place in primary-care settings (Vedel et al., 2011), GPs have implicitly been given the responsibility for guiding men's decisions about whether or not they should have a PSA test to screen for prostate cancer. In Australia - where there is no organised programme of PSA screening but opportunistic testing in clinical settings is common (Australian Institute of Health and Welfare (AIHW), 2013) - these interactions are typically construed through a doctor-patient relationship. Recent research in Australia indicates that men receive different care depending on how their GP understands and seeks to discharge his or her responsibilities for PSA testing (Pickles et al., 2015).

Research consistently shows that while many patients prefer to share healthcare decisions with their treating doctor (Benbassat et al., 1998), individuals also vary in how much they wish to concern themselves with the relevant evidence (Deber et al., 2007; Doherty et al., 2015). Negotiating these differences, while seeking to explain the complexity of PSA screening, creates complications for effective communication and decision-making (Clements et al., 2007; Linder et al., 2014). Studies of prostate cancer screening in primary-care settings have mainly focused on factors that influence GP and patient attitudes towards and decisions about PSA testing (Archer and Hayter, 2006; Finney Rutten et al., 2005; Pollack et al., 2012; Purvis Cooper et al., 2004). This body of research provides key insights into variations in how GPs and patients reason and communicate about PSA testing, but does little to illuminate their perspectives on the normative dimensions of these clinical encounters. Heterogeneity in GP practices and ambiguity about GP roles, and who is responsible for decisions on whether or not to screen for prostate cancer, are all key issues in the broader PSA debate (Han et al., 2013; Wheeler et al., 2011). Yet what such responsibility entails and how attributions of responsibility can be justified are rarely explicated (Munthe et al., 2012).

\section{Making sense of responsibility in decision-making}

Almost 40 years ago, the legal and political philosopher HLA Hart (1968) identified that normative claims about responsibility often fail to have substantial impacts upon the world because the term can be construed to have different meanings and ethical valences in ordinary language use. Claims about responsibility rest on assumptions that an agent's choices and actions are necessary links in the causal chain that produce a specific outcome. However, the traits or characteristics of the agent are also important. For an agent 
to be responsible is generally thought to depend on them meeting a set of capacity criteria such as prior knowledge, rationality, and the possibility that the agent could do otherwise. Notably, most accounts of autonomy depend on similar criteria; the concepts are intertwined such that basic autonomy and normative competence are often held to be the minimal condition for being responsible (Christman, 2015). While modern concepts of responsibility seem to rest on a notion of agency - a special type of control that only those held accountable can exercise - whether it even makes sense to ascribe responsibility to agents in a (at least partly) deterministic world is the subject of ongoing philosophical debate (Fischer and Ravizza, 2000; Strawson, 1994). The net effect is that despite the frequency and normative force of attributions of responsibility, the implicitness of assumptions and the ambiguity of concepts-in-use have limited our understanding of responsibility in discussions about clinical decision-making.

There are a number of different typologies of responsibility, each of which attempts to capture the way in which we can meaningfully ascribe praise or blame to agents (Fischer and Ravizza, 2000; Hart, 1968). The philosopher Nicole Vincent (2011) has attempted to capture, disambiguate and codify the nature and meaning of different responsibility concepts in a structured taxonomy. Both drawing on and synthesising key contributions to philosophical discussions, she identifies six interrelated but subtly different concepts that are commonly described as 'responsibility' in ordinary language use. They are as follows:

Virtue-responsibility. To call somebody 'responsible' in this sense is to say something good about their character, reputation or intentions, as exemplified by their previous conduct and commitment to doing what they take to be right. The opposite of this description is to be irresponsible, which is to lack this virtue

Role-responsibility. It refers to the duties attached to a person in virtue of their institutional, social or moral position. In this context, the term is forward-looking and prescriptive - it describes what a person ought and ought not do, and any expectations held for which their failure to act will rightfully attract moral criticism.

Outcome-responsibility. It refers to outcomes for which a person is held responsible. In this context, the term is descriptive and backward-looking and can apply events and states of affairs attributable to something people or institutions have done (or failed to do). Notably, this use of the term closely resembles most philosophers' conception of moral responsibility.

Causal-responsibility. It is similar to outcome-responsibility, but carries less normative weight. It refers to causal links between events and states of affairs such that the term is being used as a synonym for a 'cause' or 'condition'. In this context, the concept of 'responsibility' is being used to highlight that person's actions have significance to producing a specific outcome, without being completely morally responsible in the sense described above by 'outcome-responsibility'.

Capacity-responsibility. It refers to the threshold above which agents can be held responsible because they have capacity to make realistic and voluntary choices based on rational and informed thought. In this typology, capacities, which are largely cognitive, 


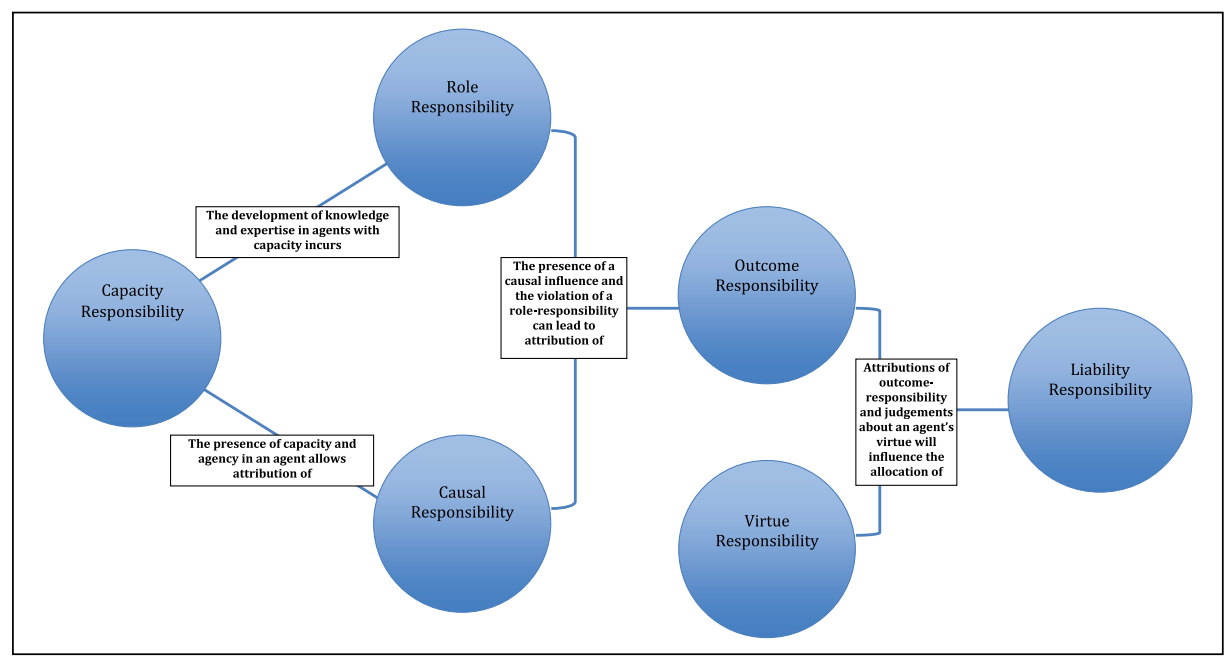

Figure I. Adapted from Vincent's (20I I: 20) structured taxonomy of responsibility concepts.

are held to be distinct from morally-relevant character traits. This allows for the disambiguation of and meaningful contrast between capacity- and virtue-responsibility.

Liability-responsibility. It refers to who will be held responsible for outcomes and the sanctions and moral burdens that will apply to the responsible agent. Judgements about liability require prior judgements of outcome- and virtue-responsibility. Vincent (2011: 18) notes that when 'responsibility' is used in this way, 'it is usually coupled with another word - i.e. take responsibility or hold responsible - and it refers to the things that someone must do, or how they should be treated, to set things right'.

Arguably, Vincent's (2011) main contribution is that her taxonomy brings each of the responsibility concepts into a structured relationship. It allows us to begin to understand how attributions of one type of responsibility can influence and potentially justify attributions of the others. To help explain the nature of these interactions, we have adapted Vincent's original diagram by adding a description of relationships between the different concepts (Figure 1). When supported by specific goals and well-defined sets of social norms or standards, each of these responsibility concepts can also be brought to bear in evaluating interactions between agents (people and institutions). The social norms and goals that sit in the background of attributions of praise or blame for outcomes and actions are important because they determine the role-responsibilities and types and level of capacity that are reasonably held to impose duties on agents. Taken together and contextualised in this manner, the six concepts and the relationships between them seek to capture key aspects of the socio-ethical and epistemological environments in which judgements about responsibility are made.

For example, as Figure 1 illustrates, claims that an agent is responsible for an outcome depend on prior claims about their causal- and role-responsibilities, and conclusions about both of these hinge on judgements about the agent's capacity. Judgements about capacity are typically subject to a threshold - agents either do or do not have sufficient capacity to be 
held responsible for their specific role, causal influence or both, in producing an outcome. Judgements about capacity also indicate what kinds of roles are appropriate for agents to take or highlight when attributions of outcome-responsibility are inappropriate. Therefore, to be held responsible for an outcome, an agent must, at a minimum, have capacity, have a causal role and violate their role-responsibilities without a valid reason for doing so.

Vincent's structured taxonomy has the potential to bring clarity to discussions and debates where 'who' is rightfully to be held responsible for 'what' remains a point of contention. The norms surrounding PSA testing and the role-responsibilities of experts and asymptomatic men in screening decision-making are still very much in flux. Recommendations about its use are increasingly predicated on ensuring effective communication and informedor shared-decision-making (IDM/SDM). Numerous models of IDM/SDM making for PSA screening have been put forward (Volk et al., 2007). However, recent reports indicate it is not routinely used in practice or inconsistently applied (Couët et al., 2013; Han et al., 2013). More generally, there is a lack of clarity as to how healthcare providers and patients can meaningfully take part in IDM/SDM (Doherty et al., 2015; Sandman and Munthe, 2010), and neither the core competencies for GPs nor the appropriate triggers for IDM/SDM during consultations have been formalised (Ferrer and Gill, 2013). Because expectations of responsibility in IDM/SDM are under-conceptualised, we sought information on how informed publics allocate roles and responsibility for PSA screening decisions.

\section{Methods}

A community jury is a process in which a broadly representative group of citizens or service users are brought together to be educated about and deliberate on a specific issue (Degeling et al., 2015a). What distinguishes such deliberative methods from other research methodologies for eliciting public views is the creation of a structured and constructive process of information exchange and knowledge-making between experts and members of the public. In this study, we convened two community juries to hear testimony from and ask questions of expert witnesses who provided a range of views on the value and risks of the PSA test and Australian ethical-legal requirements for informed consent. We then invited jurors to deliberate and vote on two related questions:

\section{Question A: Select 1 or 2}

1. Should GPs introduce the topic of PSA testing during appointments with male patients who have no symptoms?

OR

2. Should they wait until men ask about it?

Question B: Which of these options do you endorse? (Please give your reasons)

1. Men without symptoms should get all the information about the possible benefits and harms of testing, and biopsy and treatment, before they decide whether or not to have a PSA test.

OR 
Table I. Characteristics of jury participants.

\begin{tabular}{|c|c|c|}
\hline & Jury I $(n=15)$ & Jury $2(n=12)$ \\
\hline \multicolumn{3}{|l|}{ Age (years) } \\
\hline$<40$ & 5 & I \\
\hline $40-70$ & 8 & 9 \\
\hline$>70$ & 2 & 2 \\
\hline Range & $19-75$ & $37-74$ \\
\hline Median & 49 & 57 \\
\hline \multicolumn{3}{|l|}{ Gender } \\
\hline Male & 9 & 12 \\
\hline Female & 6 & 0 \\
\hline \multicolumn{3}{|l|}{ Highest educational attainment } \\
\hline High school & 3 & I \\
\hline Trade/diploma & I & 7 \\
\hline Bachelor degree & 7 & 3 \\
\hline Postgraduate degree & 4 & 1 \\
\hline \multicolumn{3}{|l|}{ Cultural background/ethnicitya } \\
\hline Australian & $\mathrm{II}$ & 7 \\
\hline Southern/Eastern European & 1 & 0 \\
\hline South-East Asian & 0 & I \\
\hline North-East Asian & 2 & 2 \\
\hline Southern/Central Asian & I & I \\
\hline North-West European & 0 & 1 \\
\hline \multicolumn{3}{|l|}{ Socio-economic status of suburb } \\
\hline Low & 1 & 2 \\
\hline Middle & 4 & 4 \\
\hline High & 10 & 6 \\
\hline
\end{tabular}

aBased on Australian Standard Classification of Cultural and Ethnic Groups (ASCEG).

'Based on Socio-Economic Index for Area (SEIFA).

2. Men should not get information about possible benefits and harms of biopsy and treatment before PSA testing. Instead, the doctor should wait until they know the test result. If the test result is raised, then the doctor should give information.

\section{Recruitment}

A total of 27 participants of diverse background with no experience of prostate cancer were recruited via social and news media: one jury with mixed genders and ages and one all-male jury of screening age. While we sought to include participants from diverse educational, social and cultural backgrounds, final group composition was also determined by volunteer availability (Table 1$)$. The first jury $(n=15,9$ males and 6 females) was socio-culturally diverse and included participants with above average level of educational attainment; the final all-male jury $(n=12)$ was more socially and culturally diverse and broadly representative of the average level of educational attainment in the 
Australian population. Our study was approved by the Cancer Institute of NSW: HREC/12/CIPHS/46.

Each jury was held over a weekend and commenced with an orientation session on the Friday evening where participants were introduced to the questions to be deliberated, and consent to participate was obtained. Day 1 of the jury focused on hearing expert witnesses, interrogating the evidence on the PSA test and understanding the ethico-legal and practical issues that surround informed consent in medical practice. Expert witness sessions ran for approximately an hour with the experts available following the presentation so that jurors could ask them questions or clarify the arguments presented. Interrogation of each witness typically lasted for 30 minutes. On the second day, for the first hour the jurors reflected on, discussed and debated with the aid of a facilitator the evidence presented to them. The juries then deliberated for an hour without a facilitator present to come to a verdict on the questions posed, which was then reported to the research team in a final facilitated feedback session.

\section{Data collection and extraction}

In the final session of both juries, their findings were recorded and compiled onto a flipchart by a facilitator. Each point was then reviewed by the jury to ensure the recorded verdict was an accurate summary of their deliberations and conclusions. All jury deliberations (both facilitated and un-facilitated) and question and answer sessions were audio-recorded and transcribed in detail by a professional transcriber.

Our approach to data extraction and analysis was broadly consistent with the tenets of Framework methodologies (Gale et al., 2013). Transcripts of the jury sessions were read several times by the lead author. Open coding was used to identify the range of normative arguments, meanings and reasoning put forward by the jurors in their deliberations. Authors 1 and 2 then reviewed the annotated transcripts, and the logic and rationale of their findings were discussed by all three authors. Responsibility was identified as a central normative concept in jurors' reasoning, and the lead author sought useful conceptual models of responsibility from the literature. Vincent's (2011) structured taxonomy of responsibility concepts was identified, and all authors agreed it provided a useful Analytic Framework as it allowed greater analytic purchase on the concept of responsibility in the data. Transcripts were then analysed in further detail by the first author using Vincent's taxonomy as a framework. Talks that employed normative concepts such as 'responsibility', 'role', 'obligation', 'to owe' and 'duty' were captured and manually tabulated. Our analysis then proceeded through cycles of repeated readings, constant comparisons, discussions among all the authors, periods of testing of alternate explanations and then re-immersion within the research materials (Borkan, 1999). During our initial readings, we also noted that jurors also spoke of their own and others' 'rights', and by this they were referring to the reciprocal obligations arising from the institutional role occupied by GPs and the special relationship GPs have with their patients. Because contractual models of 'rights' entail specific responsibilities, we included interactions where jurors discussed 'rights' in our final analyses.

Drawing on Vincent's taxonomy, our analytic strategy paid attention to the ways in which jurors reasoned through and made claims about the respective roles and responsibilities of GPs and patients in communication and decision-making for PSA screening. 
As analysts, we understood that jury deliberations are essentially discussions within groups of strangers. We did not approach analysis assuming we could access the true opinions or beliefs of the participants, but recognised that the essence of deliberation is reasoning with others such that an individual's opinions can change through the course of a discussion or debate. We were interested in the positions participants took during deliberations and the underlying reasons and rationales presented by participants for why a position was seen to be important and justified.

\section{Results}

\section{The verdict - GPs should raise the topic of PSA testing with their patients}

After 2 days of considering the evidence, asking questions and deliberating, the community juries voted in the following manner. For the first question (Question $A$ ), there was a strong majority verdict in favour of the proposition that GPs should introduce the topic of PSA testing with asymptomatic men aged 50-70 in both the mixed-gender (12 votes to 3 ) and all-male (10 votes to 2$)$ juries. The rationale was that primary healthcare providers are in the best position to introduce the topic, and all men should have equal access to the same information. Jurors said GPs were a reliable point of information access. Relying on other sources would be 'leaving it to chance', meaning that some men would not know about PSA-based screening and not have the opportunity to decide for themselves. Because neither jury reached consensus, a minority of participants in both juries voted for the proposition that GPs should not introduce the topic to their asymptomatic male patients. The rationale for this minority position was that men are better off not knowing about a medical intervention about which there is such uncertainty and the risks potentially outweigh the benefits.

For the second question (Question B), the first mixed-gender jury voted 13 to 2 that GPs should inform men of the potential harms and benefits of PSA-based screening before they took the test (option 1). Notably, the second jury comprising men of screening age voted very differently to the first jury on this question, with a two-thirds majority ( 8 votes to 4 ) forming around the proposition that men should not get information about possible benefits and harms of biopsy and treatment before PSA testing. The majority of this all-male jury concluded GPs should wait until their patients receive a raised PSA test result before giving them information about further steps and possibilities (option 2). The rationales provided by the second jury for not informing men about the potential benefits and harms of PSA-based screening before testing were (1) that men should not be bombarded with complex information about a disease they may not even have and (2) that men should be able to trust their doctors to decide what was in their best interests. Further details of the jurors' findings and their implications in the Australian context are reported elsewhere (Degeling et al., 2015b).

\section{Jurors' deliberations focused on distributing role-responsibilities}

Analysis of the transcripts revealed patterned similarities and differences in how jurors reasoned about key issues surrounding GP and patient responsibilities in decision-making 
processes. In early deliberative discussions, both juries tended to construe issues surrounding PSA screening through the lens of a more traditional doctor-patient relationship. Perceived inequalities in this relationship and differences in healthcare provider and patient expertise were central to their attribution of responsibility. One participant in the first mixed-gender jury summed up the juror discussions of the position occupied by GPs:

The GPs have the power ... They have the power because they have the knowledge and when we make decisions on anything in life, you have to find out what are you basing your decision on? You've got to get the knowledge. (CJ1-day2)

As the strength of the majority verdict in favour of GPs initiating discussions with men about PSA testing indicates, making sure that all men had equal access to the same information, and opportunity to act upon it, was seen as being something that men were owed by their primary healthcare providers. While some jurors were in favour of public communication campaigns about the harms, benefits and uncertainty surrounding PSA screening, the majority held that GPs should proactively raise screening with asymptomatic men. Both of these measures were intended to ensure that citizens had access to information in a systematic rather than an arbitrary way. The jurors' deliberations around Question A centred on the institutional position of GPs and differences in knowledge between them and their patients. For these jurors, these differences created role-responsibilities for GPs to inform men about the possibility of PSA-based screening for prostate cancer:

- how can we be expected to know it's even available ... Because most patients are nonmedical people and they would not know and not know even what PSA the three letters stand for ... we have to trust the medical professional to give us that professional information. (CJ2-day2)

This requirement for sharing basic information became the first step in negotiating the distribution of responsibilities between GPs and patients. Rather than seeing the GP responsibility in isolation, both juries held that the GP's role-responsibility should vary depending on individual patient's interest in and aptitude for assuming the role of decision-maker. As the quote above illustrates, a patient's lack of expertise limits their ability to assume their own role-responsibility as an informed autonomous patient. Therefore, almost all of the jurors believed that GPs have a responsibility to manage the varying capacity of patients, as well as informing men of the possibility of PSA-based screening. However, our analyses revealed differences in juror's views on the limits of a GP's roleresponsibility and what this responsibility entailed for the reciprocal role-responsibilities of patients (Table 2). As they deliberated about both questions, jurors held and occasionally shifted between three distinct positions on the role-responsibility of GPs.

\section{Position I: GPs should support SDM}

Many jurors, particularly those in the first mixed-gender jury, argued that GPs have a role-responsibility to 'put them [patients] in a position to understand what is in their best interests' (CJ2-day2). The goal is to support men's autonomy by trying to give them 
Table 2. Positions taken by jurors during deliberation.

\begin{tabular}{|c|c|c|}
\hline & GP role-responsibilities & Patient role-responsibilities \\
\hline $\begin{array}{l}\text { Position I } \\
\text { GPs should support } \\
\text { shared decision-making } \\
\text { (for all men) }\end{array}$ & $\begin{array}{l}\text { To inform men about the } \\
\text { possibility of PSA screening } \\
\text { (R) } \\
\text { - To adapt to differences in } \\
\text { patient capacity and provide } \\
\text { as much balanced and factual } \\
\text { information as each man } \\
\text { requires (R) } \\
\text { - To work with men to make } \\
\text { sure a good decision is made } \\
\text { without being responsible } \\
\text { for the outcome of that } \\
\text { decision (R) }\end{array}$ & $\begin{array}{l}\text { To indicate to GPs how } \\
\text { much information they } \\
\text { require to make or } \\
\text { share a decision (R) } \\
\text { - To take role- } \\
\text { responsibility for } \\
\text { decision relating to } \\
\text { their health (R) } \\
\text { - To work with GPs } \\
\text { to make sure a good } \\
\text { decision is made }(\mathrm{R})\end{array}$ \\
\hline $\begin{array}{l}\text { Position } 2 \\
\text { GPs as trustworthy } \\
\text { paternalists (for all men) }\end{array}$ & $\begin{array}{l}\text { To inform men about the } \\
\text { possibility of PSA screening } \\
\text { (R) } \\
\text { - To use their expertise to } \\
\text { evaluate the evidence and } \\
\text { judge what is best based } \\
\text { on each man's individual } \\
\text { circumstance and advise } \\
\text { their patients accordingly } \\
\text { (R) } \\
\text { To fulfil this role- } \\
\text { responsibility by remaining } \\
\text { abreast of the latest } \\
\text { evidence and always use } \\
\text { it to act in their patients' } \\
\text { interests (I) }\end{array}$ & $\begin{array}{l}\text { - To seek out and consult } \\
\text { those with relevant } \\
\text { expert knowledge, that } \\
\text { is, GPs (I) } \\
\text { - To ensure that their } \\
\text { GP is trustworthy while } \\
\text { also accepting there are } \\
\text { limits to expertise (R) } \\
\text { - To take outcome- } \\
\text { responsibility for their } \\
\text { role in choosing which } \\
\text { GP will make decisions } \\
\text { on their behalf (R) }\end{array}$ \\
\hline $\begin{array}{l}\text { Position } 3 \\
\text { IF men do not ask, THEN } \\
\text { GPs should shelter men } \\
\text { BUT } \\
\text { IF men do ask THEN } \\
\text { GPs should inform men } \\
\text { and then divest decision- } \\
\text { making to them }\end{array}$ & $\begin{array}{l}\text { - To protect men from } \\
\text { the risks of unnecessary } \\
\text { interventions by not raising } \\
\text { the topic of PSA testing (R) } \\
\text { - OR } \\
\text { - Inform any man who } \\
\text { expresses an interest in } \\
\text { being screened about ALL } \\
\text { of the potential harms and } \\
\text { benefits (R) }\end{array}$ & $\begin{array}{l}\text { - To accept that doctors } \\
\text { know what is best for } \\
\text { most men (R) } \\
\text { - OR } \\
\text { - To take complete } \\
\text { role- and outcome- } \\
\text { responsibility for their } \\
\text { own screening } \\
\text { decisions (I) }\end{array}$ \\
\hline
\end{tabular}

GP: general practitioner; PSA: prostate-specific antigen; R: result directly reported; I: result inferred from nature of conversations.

enough knowledge for informed choice. Consequently, the GP's role-responsibility only extends to initiating discussion and providing as much balanced and factual information as their patients want - the GP is not responsible for men's decisions because 'patients are the best people to look after their own health, and everything should flow from that' 
(CJ1-day1). Jurors who held this position put a high value on patient sovereignty, which meant they also thought the decision about the level of detail required 'should be in the patient's hands ..., not in the doctor's'(CJ1-day2). Yet there was also an explicit acknowledgement that there are limits on how much autonomy patients could realistically achieve. GPs are still responsible for deciding what information is most relevant to each patient's situation and staging its delivery so that men have time to consider their options before either sharing or making their own decision because 'consent and autonomy are not things that happen overnight' (CJ1-day2).

At the times during deliberation when this position was being debated, discussions were often couched in terms of 'rights'. Foremost among the rights invoked was a man's 'right to know what's available to them' (CJ2-day2) and to know about their own bodies. It was 'not the doctor's right to decide when and where that information should be distributed' (CJ1-day2). Capturing the central tenet of this position that patients ultimately must occupy the role of final decision-maker, one participant in the all-male jury argued,

I mean you're just there to hear information. And there - there's no compulsion or obligation [for patients] ... to undergo that test or not. So see - it's a choice, it's a choice you make. (CJ2-day2)

\section{Position 2: GPs as trustworthy paternalists}

For others jurors, it was the GP's role-responsibility to inform men about the PSA tests and use their expertise to make the decision or at least provide a strong recommendation as to whether an individual should be tested - because 'that's what they get paid for' (CJ1-day2). Jurors supporting this position, especially among the second all-male jury, were strongly resistant to GPs insisting on involving men in complex SDM processes about screening, which they saw as an abrogation of GPs' responsibilities as expert healthcare providers. They saw the processes of evidence evaluation and decision-making as

... the doctor's job. You're not a doctor. The doctor's got the responsibility, not you. (CJ2-day2)

Jurors in the second all-male jury argued that burdening men with too much complicated information at the outset about biopsy and treatments that may or may not be required was a waste of time. One juror described it as follows:

... like putting the cart before the horse, you don't have a problem with it, why - why worry? It's only when you have problems then you find out more. I mean I'd love to know lots about lots of everything; I just don't have the time. (CJ2-day2)

Jurors recognised that patients who want this type of relationship with their GPs and rebuff attempts at information sharing must rely on their healthcare provider's medical expertise. Consequently, the GP's virtue-responsibility was particularly important for jurors who held this position, with one male participant in Jury 2 noting, 
If I go to my doctor and I ask for a PSA test, I don't need to have a barrister there with me to make sure that I'm read my rights before he takes the PSA test. I trust the doctor ... You change your doctor if you don't trust him. (CJ2-day1)

According to this account, GPs should accept a limited role-responsibility, but not outcome-responsibility, for men who clearly do not want to understand all the issues. Jurors who supported this position acknowledged that by implication, men who saw their role-responsibility as choosing a trustworthy expert decision-maker must live with the consequences of their GP's screening decisions. Because the key decision for men is whether or not to trust their GP, it was important this trust is rewarded by GPs trying to fulfil their decision-making role-responsibilities meritoriously.

\section{Position 3: GPs should either shelter men OR inform men and then divest decision-making to them}

A small minority of jurors argued that a GP's role-responsibility was to tell their patients either 'everything or nothing about the PSA test' (CJ1-day2) before a screening decision is made. They maintained that anything in between only created partial knowledge in patients - which may lead to decisions that do not truly reflect the patient's preferences and values. A key feature of this account of the GP's responsibilities is that the preferred alternative for dealing with men's screening decisions was, in the words of one juror, to 'keep them ignorant' (CJ1-day2) and therefore, hopefully, out of harm's way. However, if an individual patient cannot be sheltered from knowledge of the PSA test, as the licensed gatekeeper 'the doctor shouldn't do the test unless he's definite that the patient understands all of the repercussions' (CJ1-day1). Differing significantly from the first position described above, jurors adopting position 3 argued that men who ask about the test 'can't decide how much [information] they want - they get everything or they get nothing' (CJ1-day2). The goal is to remove the possibility of ad hoc and selective information provision on the part of practitioners and minimise any patient perceptions of a positive bias towards PSA screening. Jurors who held this position were more likely to vote against the proposition that GPs should introduce the topic of PSA testing with asymptomatic men (Question $A$ ).

According to this account, GPs should not automatically seek to share decision-making but rather should shelter men from needing to make that difficult choice. While deliberately withholding information may seem morally troubling, this mirrors the position held by the USPSTF and RACGP that there is no obligation (moral, legal or otherwise) for primary-care providers to inform men about something that is likely to do them more harm than good. When sheltering is not possible because a man has requested PSA screening, they should be presented with balanced and factual information about the pros and cons of testing, before they are handed responsibility and allowed to make their own informed decisions. In this way, role-responsibility for the decision is transferred from the GP to the patient. Notably, jurors who held this position asserted that GPs had a right to try to inform men who asked about the PSA test if that meant they could avoid liability for poor patient outcomes. Jurors who argued against this two-tiered approach noted that 
the first step 'doesn't give any rights to the patient' and the second step 'puts too much pressure on the doctor' to ensure that patients are adequately informed before a decision is made.

\section{Discussion}

Previous empirical research in the United States and Australia indicates that some GPs are acutely aware that they can attract praise or blame for their approach to PSA testing with their patients (Pickles et al., 2015; Volk et al., 2013) and that patients are also more likely to ascribe responsibility for adverse outcomes to GPs who discourage men from PSA screening than those who recommend it (Gattellari and Ward, 2004; Howard et al., 2013). The majority endorsement in both juries for GPs raising the topic of PSA testing (Question A) indicates that well-informed members of the public are likely to expect healthcare providers to ensure that all men of screening age are informed about the existence of the PSA test and the possibility of prostate cancer screening - even if those with relevant expertise believe they have valid reasons for withholding this information. The central value underpinning this position was the need for equality of opportunity to know about the potential to screen for prostate cancer and then to act upon this knowledge according to their own priorities, values and preferences.

Notably, for a significant number of jurors these preferences and values included GPs making expert judgements on behalf of their patients. In this regard, the verdicts on Question B were less clear, with the juries voting for different positions on what role GPs should take in initial screening decision-making and how they should discharge their responsibility for information provision. The first all-ages mixed-gender jury placed greater emphasis on seeking to build patient expertise and respect their right to make decisions about their own health; the second jury comprising entirely of men of screening age was more inclined towards more traditional paternalistic doctor-patient relationship. Differences in each jury's composition are a likely partial explanation of these different results; however, our analysis demonstrates there is considerable nuance in this variation. Our examination of each jury's deliberations highlights how the allocation of responsibilities in PSA screening decision-making is likely to vary depending on how patient autonomy is constructed and valued during interactions between GPs and their patients.

Respect and/or support for patients' autonomy is widely regarded as a defining principle of ethical medical care. The relationship between autonomy and responsibility is complex, not least because both concepts are contested and have a variety of formulations. Nonetheless, it is commonly held that if someone acts autonomously, a prima facie case can be made that they are also responsible - even if it is possible to argue that each is not always a sufficient condition for the other (Christman, 2015). The dominant view in the first mixed-gender jury was that supporting and respecting autonomy are about making sure men have enough knowledge to make their own decision. Decisional autonomy in this instance is not conceived as a property of individuals but as a relational and graded experience. The goal is to engage men in deliberation so that they can reflect and come to their own decision. As an ideal, this form of SDM seeks to strike a balance between patient self-realisation and professional beneficence such that the GP employs their expertise to make sure that a good decision is made (Entwistle et al., 2012). 
In contrast, the second all-male jury construed support and respect for patient autonomy as being able to give the GP permission to decide for you and assess this decision against your sense of self/what is right for you. For these jurors, information about possible future outcomes was less central to autonomy than receiving a set of justifications for the proposed course of action and having the option of rejecting it (Mendick et al., 2010; Sinding et al., 2010). Jurors who took this position argued men should be able to decline the opportunity to become a lay-expert. They wanted GPs to take role-responsibility for decisions, but not because they saw this as means of limiting their own liability. Instead, a high value was placed on GPs being trusted to know what was in their patient's best interest. Arguably, this is another form of relational autonomy, in which the GP's engagement with the patient, and knowledge of what matters to them, allows the patient to delegate decision-making to the GP. The autonomy sought here is a sense of engagement with and ownership of their health care (Kukla, 2005). Because men who want this relationship with their GP may lack, or do not wish to acquire, enough knowledge to make an informed decision about PSA testing, it may not be appropriate to force responsibility for this role on them.

Finally, a small minority of jurors proposed a two-tiered approach where men are sheltered from choices that are potentially harmful to them until the topic is raised; then the patient is treated as being an independent and fully autonomous decision-maker. The first stage of this approach exemplifies decisional paternalism (Carter et al., 2015). The GP withholds the option of PSA testing because of a judgement that this will prevent men's well-being from decreasing. The second stage implements respect for a decisional form of autonomy (Mackenzie, 2014); the emphasis is on providing information than expecting patients to choose between discrete options independently (without being influenced). Notably, within this position, professional beneficence and self-determination are held as mutually exclusive - in direct contrast to the idea of 'shared' decisionmaking. First denying and then locating autonomy in the individual in this way are internally inconsistent: it begins by violating the model of autonomy that it ends up being based on. Arguably, the two-stage solution allows no middle ground: either GPs or men are forced to take on complete role-responsibility and, depending on prevailing social norms, all that this entails in terms of being held responsible for decision outcomes.

There are risks in all of the different ways of seeking to support men in their decisionmaking about PSA screening (Sandman and Munthe, 2010). Some critics suggest that SDM amounts to an attempt to avoid institutional accountability because it combines an increase in patient power with increased responsibility as decision-maker (Barnes et al., 2007). This relies on the creation and valorisation of new types of 'responsible patients' who are empowered in some ways but also potentially more vulnerable in others. If not properly supported, patients who take on this role can suffer from information overload, misconceive the evidence and become blocked and anxious about the burden of that responsibility (Entwistle et al., 2012). This reinforces the observation central to the position taken by the second all-male jury that it might be unfair to involve men in some forms of decision-making - especially if the development of this role is overly onerous for the patient and disrupts what they value in relationships with healthcare providers (Munthe et al., 2012). Yet Vincent's taxonomy suggests it is also conceivable that a GP could be held morally, if not legally, responsible for failing to attempt to build knowledge 
and expertise, if the decision is seen to be causally relevant to an unfavourable outcome for the patient. Consequently, if men have a right to know about the PSA test, then men may have a responsibility to tell GPs how much information they want and what role they are comfortable with assuming. This also suggests that men's right to refuse testing or information about testing places limits on the GP's responsibility for patient outcomes. That said, if some men want to trust their GPs so much as to think that the offer of the test is sufficient justification for them to accept, then it is essential that GPs have sufficient evidence that the potential benefits of testing outweigh the potential harms, which is currently not the case for PSA screening.

\section{Strengths and limitations}

Community juries are not intended to be statistically representative of the wider population - they do, however, offer valuable insights on the range and nature of informed views of citizens and service users (Degeling et al., 2015a). Possible limitations include the focus on urban Sydney, as juries drawn from other settings and locations may weigh up and value the potential harms and benefits of PSA-based screening differently.

\section{Conclusion}

Our results show an informed public may resist or embrace attempts to involve them in decision-making processes, particularly in the context of uncertain evidence. Role allocation in decision-making processes is likely to be strongly affected by the capacities of individual men and also what they value most in their relationships with primary healthcare providers. Although the policy context for PSA testing varies around the world, these findings have implications for practice and policy. It is commonly held that it is the responsibility of those offering the screening test to provide information about the potential harms and benefits of testing (Andermann et al., 2008). However, both in Australia and internationally, there are clear differences in how GPs, statutory authorities and professional bodies construe their obligations to ensure men at risk of prostate cancer receive appropriate care (Knight, 2014; Pickles et al., 2015). Our detailed analysis of jury deliberations highlights that even when they are well-informed about the issues, ordinary members of the public and potential PSA screening service users can also hold rationally defendable yet diverse and even opposing positions.

Almost all jurors thought that having a PSA test was a difficult choice for which men needed to take personal responsibility - which concurs with findings of a previous community jury held on the Gold Coast in Australia (Rychetnik et al., 2014). However, our study suggests that what this responsibility entails can vary from full participation in SDM to full delegation to GPs. Qualitative analysis of in-depth interviews with 32 Australian GPs indicates that primary healthcare providers also hold a range of positions on how to responsibly manage PSA testing in their patients (Pickles et al., 2015). These range from seeing testing as an absolute obligation, through to fully accept the risks of under-testing with advising against it. Therefore, it is likely that the allocation of roles and responsibilities between GPs and men in PSA screening decisions must rely on individual negotiations and that this could lead to miscommunication or even conflict unless 
it is handled consciously and carefully. SDM is being proposed as the ideal approach to the dilemmas posed by PSA testing, yet a one-size-fits-all solution is likely to undermine some men's autonomy. The findings of this study may offer valuable insights to inform such discussions.

\section{Declaration of Conflicting Interests}

The author(s) declared no potential conflicts of interest with respect to the research, authorship, and/or publication of this article.

\section{Funding}

The author(s) disclosed receipt of the following financial support for the research, authorship, and/ or publication of this article: This work was supported by the National Health and Medical Research Council of Australia (BLINDED).

\section{References}

Andermann A, Blancquaert I, Beauchamp S, et al. (2008) Revisiting Wilson and Jungner in the genomic age: A review of screening criteria over the past 40 years. Bulletin of the World Health Organization 86(4): 317-319.

Archer J and Hayter M (2006) Screening men for prostate cancer in general practice: Experiences of men receiving an equivocal PSA (prostate specific antigen) test result. Primary Health Care Research and Development 7(2): 124-134.

Australian Institute of Health and Welfare (AIHW) (2013) Prostate cancer in Australia. Available at: http://www.aihw.gov.au/WorkArea/DownloadAsset.aspx?id=60129545133

Barnes M, Newman J and Sullivan HC (2007) Power, Participation and Political Renewal: Case Studies in Public Participation. Bristol: The Policy Press.

Benbassat J, Pilpel D and Tidhar M (1998) Patients' preferences for participation in clinical decision making: A review of published surveys. Behavioral Medicine 24(2): 81-88.

Borkan J (1999) Immersion/crystallization. In: Crabtree B and Miller W (eds) Doing Qualitative Research. London: SAGE, pp. 179-194.

Carter S, Entwistle V and Little M (2015) Relational conceptions of paternalism: A way to rebut nannystate accusations and evaluate public health interventions. Public Health 129(8): 1021-1029.

Chou R, Croswell JM, Dana T, et al. (2011) Screening for prostate cancer: A review of the evidence for the US preventive services task force. Annals of Internal Medicine 155(11): 762-771.

Christman J (2015) Autonomy in moral and political philosophy. In: Zalta EN (ed.) Stanford Encyclopedia of Philosophy (Spring 2015 edition). Available at: http://plato.stanford.edu/ archives/spr2015/entries/autonomy-moral/

Clements A, Watson E, Rai T, et al. (2007) The PSA testing dilemma: GPs' reports of consultations with asymptomatic men: A qualitative study. BMC Family Practice 8(1): 35.

Couët N, Desroches S, Robitaille H, et al. (2013) Assessments of the extent to which healthcare providers involve patients in decision making: A systematic review of studies using the OPTION instrument. Health Expectations 18: 542-561.

Deber RB, Kraetschmer N, Urowitz S, et al. (2007) Do people want to be autonomous patients? Preferred roles in treatment decision-making in several patient populations. Health Expectations 10(3): 248-258.

Degeling C, Carter S and Rychetnik L (2015a) Which public and why deliberate? - A scoping review of public deliberation in public health and health policy research. Social Science \& Medicine 131: 114-121. 
Degeling C, Rychetnik L, Pickles K, et al. (2015b) "What should happen before asymptomatic men decide whether or not to have a PSA test?" A report on three community juries. The Medical Journal of Australia 203(8): 335-335.

Doherty C, Stavropoulou C, Saunders MN, et al. (2015) The consent process: Enabling or disabling patients' active participation? Health. Epub ahead of print 20 October. DOI: 10.1177/1363459315611870.

Entwistle VA, Cribb A and Watt IS (2012) Shared decision-making: Enhancing the clinical relevance. Journal of the Royal Society of Medicine 105(10): 416-421.

Ferrer RL and Gill JM (2013) Shared decision making, contextualized. Annals of Family Medicine 11(4): 303-305.

Finney Rutten LJ, Meissner HI, Breen N, et al. (2005) Factors associated with men's use of prostate-specific antigen screening: Evidence from Health Information National Trends Survey. Preventive Medicine 40(4): 461-468.

Fischer JM and Ravizza M (2000) Responsibility and Control: A Theory of Moral Responsibility. New York: Cambridge University Press.

Gale NK, Heath G, Cameron E, et al. (2013) Using the framework method for the analysis of qualitative data in multi-disciplinary health research. BMC Medical Research Methodology 13: 117 .

Gattellari M and Ward JE (2004) Will men attribute fault to their GP for adverse effects arising from controversial screening tests? An Australian study using scenarios about PSA screening. Journal of Medical Screening 11(4): 165-169.

Han PK, Kobrin S, Breen N, et al. (2013) National evidence on the use of shared decision making in prostate-specific antigen screening. Annals of Family Medicine 11(4): 306-314.

Hart HLA (1968) Punishment and Responsibility: Essays in the Philosophy of Law. New York: Oxford University Press.

Howard K, Brenner AT, Lewis C, et al. (2013) A comparison of US and Australian men's values and preferences for PSA screening. BMC Health Services Research 13(1): 388.

Ilic D, O'Connor D, Green S, et al. (2011) Screening for prostate cancer: An updated Cochrane systematic review. BJU International 107(6): 882-891.

Knight SJ (2014) Decision making and prostate cancer screening. Urologic Clinics of North America 41(2): 257-266.

Kukla R (2005) Conscientious autonomy: Displacing decisions in health care. Hastings Center Report 35(2): 34-44.

Linder SK, Kallen MA, Mullen PD, et al. (2014) Physician behaviors to promote informed decisions for prostate cancer screening: A National Research Network study. Journal of Cancer Education 29(2): 345-349.

Mackenzie C (2014) Three dimensions of autonomy: A relational analysis. In: Veltman A and Piper M (eds) Autonomy, Oppression and Gender. New York: Oxford University Press, pp. $15-41$.

Mendick N, Young B, Holcombe C, et al. (2010) The ethics of responsibility and ownership in decision-making about treatment for breast cancer: Triangulation of consultation with patient and surgeon perspectives. Social Science \& Medicine 70(12): 1904-1911.

Moyer VA (2012) Screening for prostate cancer: US Preventive Services Task Force recommendation statement. Annals of Internal Medicine 157(2): 120-134.

Munthe C, Sandman L and Cutas D (2012) Person centred care and shared decision making: Implications for ethics, public health and research. Health Care Analysis 20(3): 231-249.

Pickles K, Carter SM and Rychetnik L (2015) Doctors' approaches to PSA testing and overdiagnosis in primary healthcare: A qualitative study. BMJ Open 5(3): e006367. 
Pollack CE, Platz EA, Bhavsar NA, et al. (2012) Primary care providers' perspectives on discontinuing prostate cancer screening. Cancer 118(22): 5518-5524.

Purvis CC, Merritt TL, Ross LE, et al. (2004) To screen or not to screen, when clinical guidelines disagree: Primary care physicians' use of the PSA test. Preventive Medicine 38(2): 182-191.

Robertson M, Moir J, Skelton J, et al. (2011) When the business of sharing treatment decisions is not the same as shared decision making: A discourse analysis of decision sharing in general practice. Health 15(1): 78-95.

Rychetnik L, Doust J, Thomas R, et al. (2014) A Community Jury on PSA screening: What do well-informed men want the government to do about prostate cancer screening - A qualitative analysis. BMJ Open 4(4): e004682.

Saba GW, Wong ST, Schillinger D, et al. (2006) Shared decision making and the experience of partnership in primary care. Annals of Family Medicine 4(1): 54-62.

Sandman L and Munthe C (2010) Shared decision making, paternalism and patient choice. Health Care Analysis 18(1): 60-84.

Schwartz LM, Woloshin S, Fowler, et al. (2004) Enthusiasm for cancer screening in the United States. JAMA: Journal of the American Medical Association 291(1): 71-78.

Sinding C, Hudak P, Wiernikowski J, et al. (2010) 'I like to be an informed person but ...' negotiating responsibility for treatment decisions in cancer care. Social Science \& Medicine 71(6): 1094-1101.

Squiers LB, Bann CM, Dolina SE, et al. (2013) Prostate-specific antigen testing: Men's responses to 2012 recommendation against screening. American Journal of Preventive Medicine 45(2): $182-189$.

Strawson G (1994) The impossibility of moral responsibility. Philosophical Studies 75(1): 5-24.

Vedel I, Puts MTE, Monette M, et al. (2011) The decision-making process in prostate cancer screening in primary care with a prostate-specific antigen: A systematic review. Journal of Geriatric Oncology 2(3): 161-176.

Vincent NA (2011) A structured taxonomy of responsibility concepts. In: Vincent N, Van de Poel I and Van den Hoven J (eds) Moral Responsibility: Beyond Freewill and Determinism. Dordrecht: Springer, pp. 15-35.

Volk RJ, Hawley ST, Kneuper S, et al. (2007) Trials of decision aids for prostate cancer screening: A systematic review. American Journal of Preventive Medicine 33(5): 428-434.e411.

Volk RJ, Linder SK, Kallen MA, et al. (2013) Primary care physicians' use of an informed decision-making process for prostate cancer screening. Annals of Family Medicine 11(1): 67-74.

Wheeler DC, Szymanski KM, Black A, et al. (2011) Applying strategies from libertarian paternalism to decision making for prostate specific antigen (PSA) screening. BMC Cancer 11(1): 148.

Wilt TJ, Scardino PT, Carlsson SV, et al. (2014) Prostate-specific antigen screening in prostate cancer: Perspectives on the evidence. Journal of the National Cancer Institute 106(3): dju010. DOI: $10.1093 /$ jnci/dju010.

\section{Author biographies}

Chris Degeling is a Social Scientist, Philosopher and Veterinarian with expertise in deliberative and qualitative methods and normative analysis. Currently a Research Fellow at the Centre for Values, Ethics and the Law in Medicine at the University of Sydney, his research focuses on the social and ethical dimensions of public health policy development and implementation and the politics of risk in disease prevention.

Stacy M Carter's background is in public health. Her research focuses on public health ethics with a special interest in the ethics of health promotion, including social marketing. She is also working 
on screening ethics, over-diagnosis and too much medicine, de-prescribing in older people, relational conceptions of paternalism, methodology for empirical bioethics and qualitative inquiry, and deliberative methods. Stacy is a qualitative researcher with a particular interest and expertise in grounded theory. She is the Deputy Director of the Centre for Values, Ethics and the Law in Medicine and Associate Editor for the OUP journal Public Health Ethics.

Lucie Rychetnik has over 20 years of experience in translating research for public health policy and practice, conducting empirical research on the use of evidence in population health, chronic disease prevention and clinical settings, and leading methodological work on evidence synthesis and appraisal for public health decisions. She is Adjunct Professor (translation research) with the School of Medicine at the University of Notre Dame, Investigator with the Australian Prevention Partnership Centre (2013-2018) and Senior Advisor to the Knowledge Exchange Division of the Sax Institute, Sydney. 